\title{
DIGITAL ME IN A VIRTUAL WORLD: IDENTITY CONSTRUCTION ON LINKEDIN BY AOTEAROA/NEW ZEALAND ENTREPRENEURIAL PROFESSIONALS
}

\author{
Sandra Jane Barnett ${ }^{1}$ \\ Manukau Institute of Technology, New Zealand \\ ${ }^{1} \mathrm{Dr}$
}

\begin{abstract}
This study explores if, and how, the business social media site, LinkedIn, is providing for Aotearoa/New Zealand entrepreneurial professionals an alternative site for the construction of identity, and the tensions experienced in this process. The framework of exploration is based on identifying tensions in authentic online identity construction.

A two-dimensional model of these tensions is developed from the layers of sub-tensions, tensions and meta-tensions identified. In one dimension are identity tensions inherent in the specific context; in a different dimension are meta-identity tensions that have been identified in organisational contexts but are foregrounded in this virtual context. The presence of these identity tensions confirms LinkedIn is becoming a site for professional identity construction. The study concludes with a discussion of how identifying and managing these tensions can be applied to tertiary education courses and to inform small business owners about LinkedIn use.
\end{abstract}

\section{KEYWORDS}

Linkedin, Social Media, Identity, Authenticity, Tensions

\section{INTRODUCTION}

Identity, both personal and social, is a major human preoccupation. Identity construction is an important process for situating individuals within the social landscape, and to answer the question, 'who am I'? Work or occupational identity has long been recognised as an important facet of an individual's identity (Albert \& Whetten, 1985; Erickson, 1974; Watson, 2008), and the workplace has traditionally been the site where work identities, and to some extent personal identities, are constructed, performed, and validated (Goffman, 1959; Haslam, 2001; Oakes, 2004; Postmes, Baray, Haslam, Morton, \& Swaab, 2006). In the late $20^{\text {th }}$ and the $21^{\text {st }}$ century, organisational structures have become more fluid than in $20^{\text {th }}$ century industrialised economies; a new work order has emerged, characterised by differentiation and fragmentation (Gee, Lankshear, \& Hull, 1996). The expansion of information communication technologies (ICTs) has accelerated and facilitated change, so that increasingly, the focus of work is moving outside co-located workplaces (Ancona \& Caldwell, 1992; Kraut \& Resnick, 2011; Nardi, Whittaker, \& Schwartz, 2002). Additionally, restructuring and downsizing has led to the greater use of external consultants and contractors, often working virtually and independently. As a result, work has become more distributed and individual-centred; in addition, careers are more fragmented and dynamic, with identification individuals with organisations weakening (Kraut \& Resnick, 2011; Reedy, King, \& Coupland, 2016; Shirky, 2008). In addition the phenomenon of micro-entrepreneurship - a drive towards self-employment fuelled by the growth of the Internet and new digital technologies, has been identified as motivating a resurgence of entrepreneurialism in the current millennium, both globally and in Aotearoa/New Zealand (Clark \& Douglas, 2014; Duffy \& Pruchniewska, 2017; Fonseca, 2014; Wong, 2012).

All these trends in a world where traditional work structures of the 20th century are rapidly disappearing; the construction of work identity needs to be constantly re-examined to be relevant in the field of organisational studies and the discipline of communication. Social media as a communication technology is 
breaking boundaries between work and non-work life, as well as boundaries between professions and global boundaries is, as Linda Putnam (2017) explains:

One big development in my discipline (communication) is the rise of social media in permeating and breaking boundaries - all kinds of questions are arising out of challenges to public-private and work-non-work as distinct boundaries. It's all about the new digital interface, convergence of media, and social media's influence in all walks of life - to the point that if you aren't situating your work in this space, you may not have a place in the discipline (communication). I think the work that people are doing on social media and its relationship to organization and organising is critical. It's about constructing a new understanding of what is going on in society and with social interactions (In Grant \& Cox, 2017, p. 192).

Changes in the nature of work are evident in the daily work experience of the participants in this study, Aotearoa/New Zealand entrepreneurial engaged on LinkedIn. They have generally moved from employment as a professional in a larger organisation to self-employment, utilising the power of the Internet and social media, including LinkedIn to do so. This study aimed to explore the construction of identity on LinkedIn as an emerging and complex organisational environment. It is therefore is boundary spanning in that it spans the disciplines of: organisational communication and new forms of organisation; ICT and social media use; identity and identity construction (entrepreneurial, professional and digital); and globalisation, by juxtaposing the globalising effect of social media with local discourse.

\section{BODY OF PAPER}

\subsection{Background and Research Approach}

The approach of this study is that social 'realities' including identity are socially constructed (Berger \& Luckman, 1966; Burr, 1995; Gergen, 1997). From this social constructionist perspective, identity is produced in the discourse of social relationships and encounters (Kuhn, 2006); it is not pre-formed in our subconscious and only reflected in, or transmitted through, communication channels (Kuhn, 2006; Mumby, 2011). Recent scholarship from a constructionist stance, conceptualises identities as fragmented, shifting, and conflicted (Ashcraft \& Mumby, 2004; Knight \& Weedon, 2014; Kuhn, 2006; Larson \& Gill, 2017; Tracy \& Trethewey, 2005). Identity then is a multiple construct, we have a number of social selves with each identity; we present a different self to different audiences, and they reflect back to us a version of ourselves as multiple selves. Through each of these identities, we present a different self, depending on the audience, for example people generally present different identities when they interact in a work context than in a social context (Ollier-Malaterre, Rothbard, \& Berg, 2013). Consideration of context in identity construction is therefore fundamental to the interpretative approach of this study; the contexts of the social media context and LinkedIn, of Aotearoa New Zealand and of the personal context of the life and career of the participants.

On social media, though we may present different identities on different sites, the boundaries between these 'virtual worlds' are permeable, and identity is also multiply-interpreted by many different audiences. Multiple roles or identities can overlap and be more difficult to keep separate in the virtual world where individuals' different identities can be viewed and interacted with by multiple and overlapping audiences (Marder, Joinson, \& Shankar, 2012; Marder, Joinson, Shankar, \& Thirlaway, 2016). This unknown audience can be an issue for the construction of personal online self, but is possibly more be more problematic in the case of the online professional self, as misjudgement or lack of knowledge of audience can have a direct immediate impact on work and career (Ollier-Malaterre et al., 2013). The selves presented on online social networks are subject to simultaneous surveillance by multiple audiences that can occur 24 hours a day via many different search engines. This issue has been variously referred to and described in the literature as: the online multiple audience problem (OMAP) (Marder et al., 2016), context collapse (Marwick \& Boyd, 2011), the problem of conflicting social spheres (Binder, Howes, \& Smart, 2012), and the bridging of multiple heterogeneous social communities (DiMicco \& Millen, 2007). 
Another salient context is that of LinkedIn. As an online business networking site it has characteristics that are distinct from face to face networking: connections are made by explicit agreement, connections are publicly displayed, and they create a unique social world around each individual, regulated by the individual, and interaction only occur where there is an explicit digital connection (Papacharissi, 2011). In addition the context of LinkedIn is both local and global, in that it is worldwide, however, the participants are in a local context and this dual context can create tensions between global and local discourses (Gill \& Larson, 2014a, 2014b).

As the general goal of this research was exploratory, that is to understand participants' experience of LinkedIn and how they constructed identity there, the subjective lens of interpretivism was the basis of this study. The interpretive approach, to understand the social world and human action by accessing the meanings participants assign to them, also underlies and informs the qualitative methodology. Accordingly, the research data was gathered through twenty-five in-depth semi-structured interviews conducted with those who responded to a request, on NZ SME groups on LinkedIn, to be participants and the interview transcripts were analysed through thematic analysis.

In the process of analysis, tensions, contradictions and paradoxes in identity construction emerged as a dominant concern. Tensions, such as identity tensions, have increasingly been identified a part of organisational experience (Putnam, Fairhurst, \& Banghart, 2016; Trethewey \& Ashcraft, 2004), and a growing body of literature posits that irrationality is a normal condition of organisational life, and is reflected in the tensions evident in the discourses around the construction of identity in organisations (Clarke, Brown, \& Hailey, 2009; Larson \& Gill, 2017; Tracy \& Trethewey, 2005; Woo, Putnam, \& Riforgiate, 2017). These tensions have increased as work increasingly moves to alternative or "less predictable settings of organizing"(Cheney \& Ashcraft, 2007, p. 161) such as social media. Thus, whilst social media may have eased the process of relationship building (Jussila, Kärkkäinen, \& Aramo-Immonen, 2014; Michaelidou, Siamagka, \& Christodoulides, 2011), it has also added further layers of complexity and tensions (Quinton \& Wilson, 2016; Rainie \& Wellman, 2012). This tensional approach provided the framework for analysing and interpreting the data (Barnett, 2019).

\subsection{Findings}

Analysis of the participants' interview transcripts revealed 11 main tensional themes. These tensions were: two tensions around the virtual context of identity construction, four tensions around networking and making connections, and finally, five identity construction tensions around interacting and relationship-building on LinkedIn. These tensions are collated below in Table 1 and are discussed in more detail below.

Table 1. Tensional themes in discourses about engagement, networking, and interaction

\begin{tabular}{|c|c|c|}
\hline Engagement & Networking & Interaction \\
\hline Place vs space & $\begin{array}{l}\text { Imperative to network vs } \\
\text { reluctance to do so }\end{array}$ & $\begin{array}{l}\text { Aligns with thought leaders but is also } \\
\text { original }\end{array}$ \\
\hline \multirow[t]{4}{*}{$\begin{array}{l}\text { Risk of participating vs } \\
\text { risk of not participating }\end{array}$} & $\begin{array}{l}\text { Networks as living vs networks } \\
\text { as fixed }\end{array}$ & Is an unassuming expert \\
\hline & $\begin{array}{l}\text { Openness vs closedness in } \\
\text { networking }\end{array}$ & Sells without being a salesman \\
\hline & $\begin{array}{l}\text { Displayed network vs protected } \\
\text { network }\end{array}$ & $\begin{array}{l}\text { Separates and combines personal and } \\
\text { professional identities }\end{array}$ \\
\hline & & $\begin{array}{l}\text { Wants to surveil or watch others but doesn't } \\
\text { want to surveil or watch } \\
\text { others }\end{array}$ \\
\hline
\end{tabular}

When discussing their engagement with the virtual context and social media generally, a deep underlying tension was revealed in the analysis around the participants' use of contrasting discursive resources, which simultaneously described cyberspace in language that referenced images of both 'places' and 'spaces.' On one hand, the participants' discourse alluded to cyberspace as comprising boundaried, defined, separate 
'places.' They referenced appropriate or expected behaviour and appropriate occupants to each 'place', seemingly ascribing a cultural context and imagined audience for interaction and identity presentation, based on a known or familiar context within the physical world (Boyd, 2007).

In contrast to images of 'places' within the discourses of the same individuals, a contrasting but simultaneously-held image of cyberspace was conveyed as a wide open, un-boundaried, flexible, unmappable, global, and disembodying 'space'. Participants' discourses conveyed the recurring theme that social and cultural mechanisms had not yet given clear meaning to this environment, and it was therefore chaotic, unregulated, and risky to enter, so much so that their sense of self became lost in this space, and they were unsure of where they were going in cyberspace, or why (cf.Massey, 1994).

When the analysis of the participants' discourses specifically focused on the specific context of LinkedIn, a second tension emerged, related to the first tension, but one that was considered separately to provide more insight into LinkedIn as an organisational setting. This tension was expressed in the paradox of LinkedIn being an important business tool that was necessary, risky not to use, but also risky to use, because of the many business, personal, and even social risks associated with its use, many of which echoed the concerns around context collapse.

When the analysis of the participants' discourses focused on networking through issuing and accepting invitations to connect, they indicated that online networking had opened up expansive and easy opportunities for connecting. They also felt a strong expectation, as a professional, to actively network on this site (more so now that they were a business owner or entrepreneur) and an imperative to create a digital network. However, in contradiction to this networking imperative, most participants said they preferred to, and did, limit accepting invitations to connect to people they knew, and to issue even fewer invitations themselves. They said they also did not like to be seen as networking incautiously, or even too actively or strategically.

The participants' discourse also revealed tensions around their displayed network. On one hand, they said that a large network of contacts reflected positively on their entrepreneurial professional identity. In contradiction though, they also indicated that a small, exclusive network aligned better with their sense of professional identity, and that displaying a large network may convey a message that they were not a genuine authentic professional; thus reflecting the traditional image of a professional as belonging to an exclusive network (Crane, 1972; Macdonald, 1995). Both views can be seen as consistent with the claim of Donath and Boyd (2004) that, "In this context, 'public displays of connection' present the center of identity performance and are typically viewed as a signal of the reliability of one's identity claims" (p.73). This tension around whether to display a large or limited network, illustrates the paradoxical nature of identity performance in this context. Many also expressed a trend to retreat from open active networking over time, rather than becoming habituated to it. They referred to their LinkedIn network as a database, rather than an active living framework of relationships, indicating they viewed their LinkedIn network as somewhat static. Also noted was a predominance of Aotearoa/New Zealand-born and educated participants expressing a stronger preference for passive networking (i.e. only accepting invitations and not issuing them), and a limited set of displayed connections.

When the analysis of the participants' discourses focused on interaction with others and relationship-building, their responses revealed other identity construction tensions. They expressed a need to appear to be experts and knowledgeable, but at the same time, modest and unassuming. Much of the professional identity construction work described in their discourse reflects the dominant global discourse around professionalism, for example, being polite and exclusive, and there were indications that these professional identity behaviours were being intensified online. However, there was also a cautiousness around volunteering expertise that made it difficult to present as an expert, a wariness of connecting with strangers, and a possible trend towards even greater insularity within a known group than in the physical world. There was little alignment with the dominant discourse around entrepreneurialism, of being assertive and taking risks, and this feature was more prominent in the Aotearoa /New Zealand-bred participants' discourses.

A prominent theme in the participants' discourse was that their own identity was very much aligned with the identity or brand of their business. On LinkedIn, which many referred to as a marketplace, they now felt personally responsible for getting their brand known, but there was tension in doing so, in that the process would reveal too much of their personal identity online. Additionally, they said that they needed to offer useful information to 'look the part', but not give away too much intellectual property to strangers. Furthermore, they were concerned that they may come across as 'selling' or being aggressive in marketing their business. There was also tension around the need for work or professional identity performances to be 
congruent with wider community identities and historical work identities, all of which are now publicly displayed on LinkedIn.

A further tension was evident in the participants' admission that they often viewed the LinkedIn profiles of others, even if they were not connected or did not want to connect with them. This surveillance feature of LinkedIn increased expectations that they were informed about others' background and careers as a part of their relationship-building process, but it also served to allow them to more easily reflexively evaluate their own and the careers of others, thus influencing their own identity construction. Their interest in watching others was offset by a concern that this was not polite and could be interpreted as 'stalking', creating tension around being observed as watching, or even simply knowing themselves that they were doing it. Participants stated that this behaviour was incongruent with their professional identity and even their own sense of self.

\subsection{Discussion and Interpretation}

In summary, the analysis of the participants' discourses overall revealed that LinkedIn was in fact being utilised as a site for the construction of entrepreneurial professional identity, and that this was becoming necessary and for many a normal, yet also complex and contradictory process, fraught with tensions. LinkedIn appeared to be simultaneously providing participants with a means to connect with others and construct a work/professional identity but also to be limiting their social work-world by connecting them only to those who they considered appropriate, that is, were like them. This self-boundaried world was having a regulating effect on their identity construction in this world. There were, however, divergent discourses. A few participants described actively expanding their network, curiosity about strangers, and an acceptance of and willingness to give praise and endorsements. These divergent discourses were almost exclusively from immigrants to Aotearoa/New Zealand, indicating a divergence between local contextual discourse and the wider global discourse related to professionalism and entrepreneurialism.

Further interpretation of these tensions revealed two dimensions of tensions. The first dimension related to the specific context, that is Aotearoa/New Zealand, LinkedIn, and the online entrepreneurial professional. This dimension of analysis accords with Cheney and Ashcraft (2007) advice to pay "particular sensitivity to institutional and contextual variation" (p.161) when researching identity construction in unpredictable organisational settings. The second dimension, described as meta-tensions, are more general tensional themes around identity work that surfaced in the analysis, and which align with those in prior studies in organisational communication, but which have taken on a different emphasis and character when experienced in the LinkedIn context.

The first tension in this dimension was a tension of 'space' versus 'place'. The participants in this study were negotiating with themselves and others, the meaning of the virtual world in which they interacted. This negotiation is important for identity construction if 'place' is regarded as an active character in the construction of identity (Gill \& Larson, 2014b; Sampson \& Goodrich, 2009). These different images were underscored by tension between whether this context, i.e. LinkedIn, was one of many defined 'places' for connecting and interacting online, or whether it was still an unorganised 'space'. This 'space' was an environment that had not yet been given clear meaning by social and cultural mechanisms (Massey, 1994); it lacked boundaries and regulated behaviour.

The second dialectical tension identified around the virtual context of LinkedIn as being both local and global, in that LinkedIn is worldwide, and global connection is as easy to establish as a local connection, purportedly making the world 'smaller'. However, in this study, there was global/local tension was evident in two specific aspects of the study. Firstly, when Aotearoa/New Zealand participants' discourses were contrasted with immigrants to Aotearoa/New Zealand, a tension was identified between the Aotearoa/New Zealand contextual discourse and the mainstream dominant discourse concerning entrepreneurialism and professionalism. For example, the need to be assertive and confident in communicating with others, set against the desire to be unassuming, and to not be viewed as a trying to be a 'tall poppy' (Fairburn, 1989; Sargent, 2001; Spoonley, 2014).

Secondly local/global tension was also evident in the implications of the design of LinkedIn. The technical digital context to some extent regulates identity construction work through the architecture and design of the site, a design that reflects dominant transcendent discourses around professional interaction, but these contrast with the discourses of Aotearoa/New Zealand participants around their professional interaction on LinkedIn. A prevailing assumption of the LinkedIn site's design is that, in this place, a professional or 
business person is one who grows and expands a network, and subsequently develops these relationships through assertive interaction. (e.g.Papacharissi, 2009). Despite espousing networking as an imperative, there was a reluctance to appear to need, or to be seen actively seeking out new business connections This reluctance to connect was consistently articulated more often and obviously by Aotearoa/New Zealand-born participants. This contradiction in their discourse aligns with Gill and Larson's (2014b) observations about mainstream and locale-specific discourse, i.e., "When they conflict, individuals are more likely to outwardly identify with the locale-specific discourse, yet still acknowledge the desirability of the transcendent discourse" (p.539). Such a tension between the networking imperative and reluctance to network to reflects an Aotearoa/New Zealand entrepreneurial type, where self-sufficiency and independence is valued, incongruent with the need to connect to others, implied by LinkedIn's design.

Another tension arose from the blending professionalism and entrepreneurial identity. The most prominent theme in the discourse of participants around professionalism online was the importance of being viewed as authentic. Yet being genuine and authentic as a professional, while promoting their business as an entrepreneur, was fraught with tensions.

The final tension was between bringing personal aspects to a LinkedIn identity, which then become both public and permanent (Young, 2013), and the desire to keep the personal private. This tension was increased by participants' awareness of "context collapse" (Marwick \& Boyd, 2011, p. 114).

These tensions are illustrated in Figure 2 below. The 'push-pull' effect of contrasting tensions in the context represented by the double-ended arrows is illustrated as directly or indirectly influencing the construction of identity on LinkedIn.

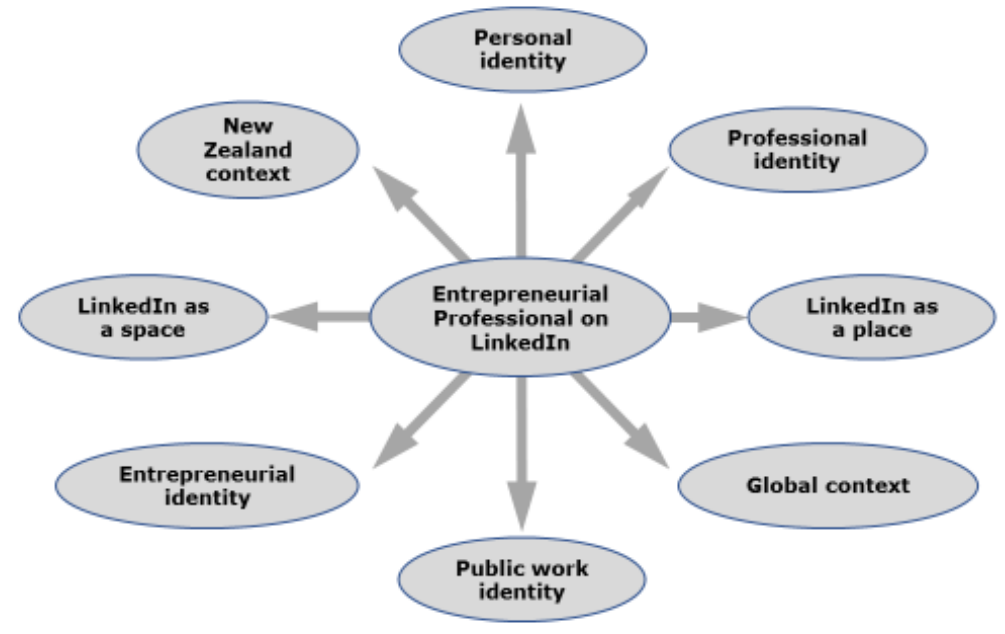

Figure 1. Dialectical tensions for an Aotearoa/New Zealand entrepreneurial/ professional on LinkedIn

In addition, these tensions are intersected in another dimension with three meta-tensions, which have already been identified in the literature on organisational identity construction (e.g.Cheney, Christensen, Ganesh, \& Zorn, 2011), but which appear to be more prominent, significant, and with a different character in the setting of LinkedIn. These tensions are: openness vs closedness, autonomy vs connectedness, and equality vs superiority. Added to these three tensions is a further tension around peer-to-peer surveillance, that is, tension between the desire to surveil others versus a reluctance to do so.

The meta-tension of openness and closedness can be seen in the tension between the risks and benefits of sharing information (Cheney et al., 2011) and the willingness, or otherwise, to merge personal and professional digital identities. Social media may increase the flow of knowledge through passive information-seeking strategies (Ramirez, Walther, Burgoon, \& Sunnafrank, 2002); however this knowledge flow on LinkedIn is limited by pressure to protect intellectual property and information that constitutes personal business brand and a reluctance to share with an audience that is somewhat unknown and therefore, untrusted. The second meta-tension, autonomy vs connectedness, is revealed in willingness, or otherwise, to accept the networking imperative. The tension of equality vs superiority is evidenced in the need to appear an expert, but to also be modest and unassuming, no better than anyone else, and even to not be 'too expert'. 
The final meta-tension revealed in the study is in an interest and need to surveil, or watch, others for information and comparison, versus a hesitancy to do so out of politeness and respect for privacy, and the fear of being detected doing this. For the LinkedIn users in this study, the information gained by surveilling others was useful in relationship-building, and being surveilled was considered welcome attention, conferring professional recognition and increased social status (Marwick, 2012, p. 389). In contrast, being noticed watching others, they said carried the risk of being viewed as eavesdropping, voyeuristic (Marwick, 2012), and impolite or violating the privacy of others (Whitworth \& Liu, 2013). These tensions are illustrated in Figure 2 below, by the double-ended arrows illustrating the push-pull effect of these identity meta-tensions in the organisational context of LinkedIn.

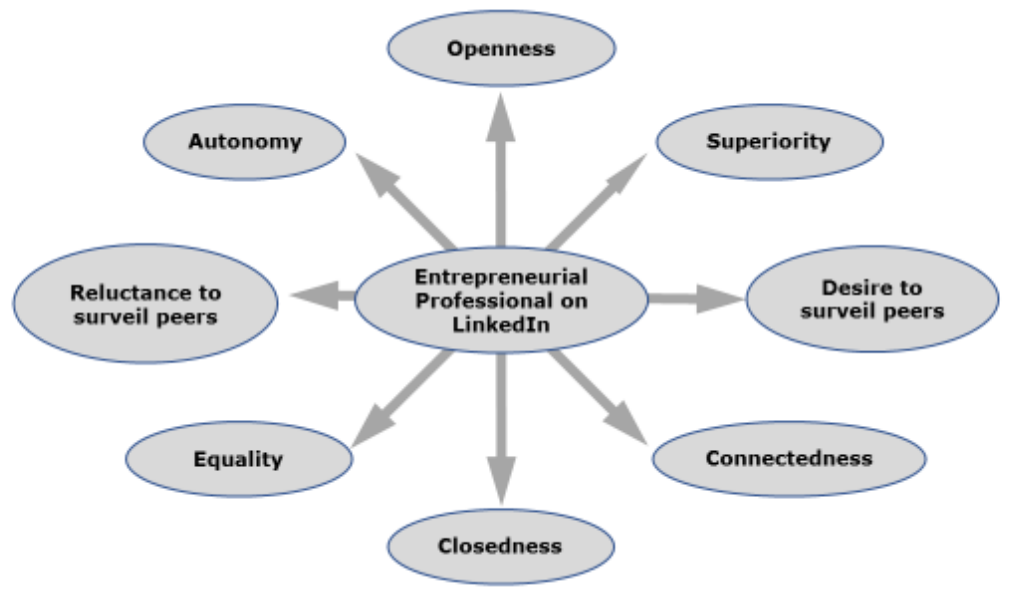

Figure 2. Meta-tensions on LinkedIn as an organisational context

A combination of these sets of dialectical tensions can be represented as intersecting tensions within these two dimensions (see Figure 3). The figure links the specific tensions experienced in constructing identity in the virtual context of LinkedIn (indicated by dotted lines) to the more general identity tensions present within organisations (indicated by a solid line).

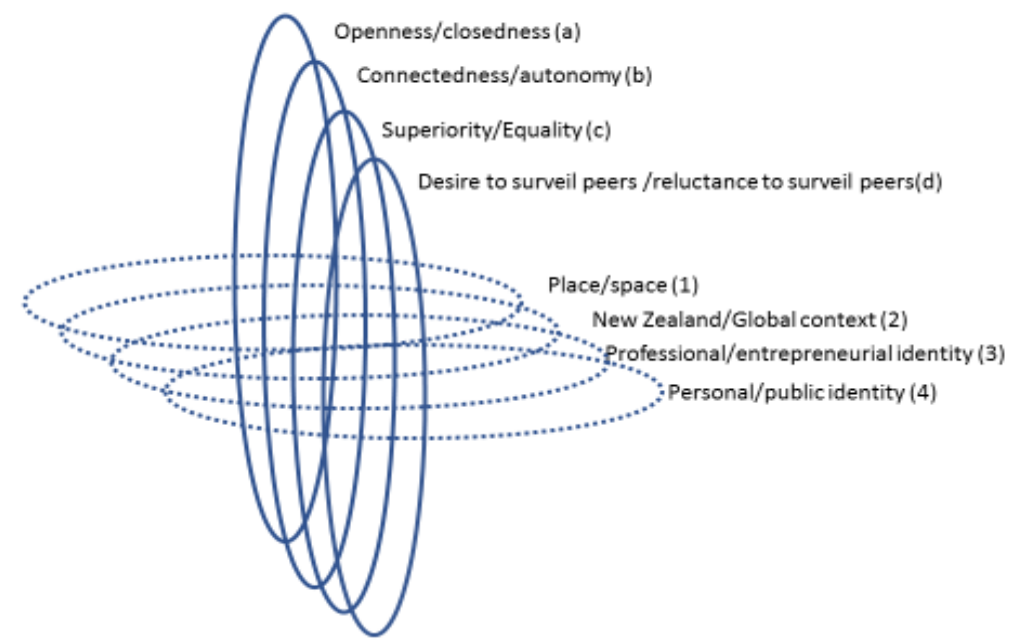

Figure 3. An integrated framework of identity construction tensions experienced by Aotearoa/New Zealand entrepreneurial/ professionals on LinkedIn

Vertical tensions interact with horizontal tensions at different levels and combine to create unique tensions for each individual. This conclusion echoes Gill's (2017) conclusion to a study of entrepreneurial identity, i.e. entrepreneurial identity resides not in the person themselves, but in the context (in the broadest sense) in which they engage. For the entrepreneurial professionals in this study, a similar conclusion can be made, although identity construction in digital contexts has become even more complex and multi-faceted, as 
social media is collapsing personal and professional, and global and local boundaries. Therefore, the tensions in constructing a digital identity are multi-faceted. Though likely to include those identified in the study, they are experienced in a unique combination for each individual and entrepreneurial/professional, depending on the situation or context. A visual conceptualisation of how these identity tensions crystallise in each individual is presented in Figure 4 below. The loops in Figure 4, signifying each identified tension (represented by numbers and letters) and in two dimensions (represented by dotted and solid lines), have been drawn out and rotated, so that that they intersect and crystallise at a central point. This point represents the unique identity tensions for an individual in a specific context.

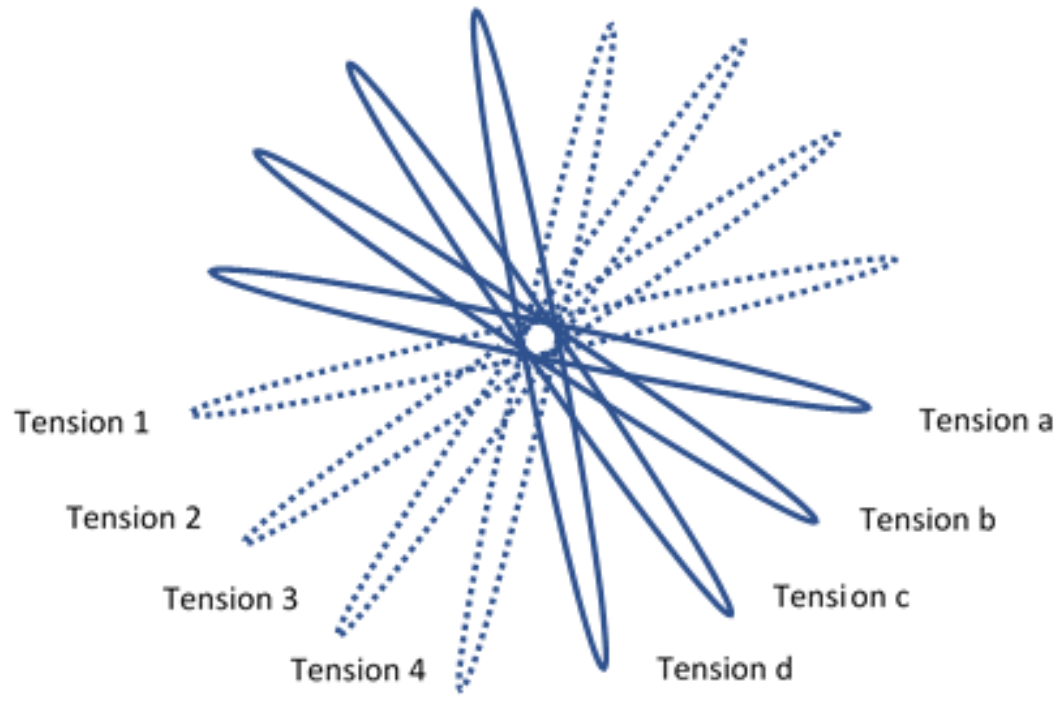

Figure 4. Conceptual image of identity construction tensions on LinkedIn for the individual

\section{CONCLUSION}

The study makes several contributions. Firstly, it identifies the tensions inherent in engaging in LinkedIn and constructing a digital identity there. Secondly, it provides evidence that LinkedIn has, in fact, become, or at least was in the process of becoming, an alternative organisational site, and thus a site for organisational identity construction. Thirdly, it presents in a multi-level and two-dimensional framework for analysis of identity construction in this context. In one dimension it suggests that identity construction on LinkedIn needs to be understood, in the context of personal work situation of the individual, of a local yet global site of communication, and in the context the unique features of a virtual social world. In another dimension, the identity construction needs to be understood as the tensions likely in an organisational setting. The research also provides some practical contributions.

The experience of these participants, and the findings around the likely tensions that arise and how they are managed, can be utilised to inform employment seminars and courses. Younger professionals are generally well-versed in using Facebook and other socially-orientated social media such as Instagram, but are generally less versed in using LinkedIn, the dominant social media site for work relationships (Florenthal \& Dykhouse, 2012; Oslund, 2010). This study interviewed experienced professional LinkedIn users, and its findings can be used to broaden training courses beyond basic training, to create a curriculum vitae on LinkedIn (cf.Paliszkiewicz \& Madra-Sawicka, 2016).

A limitation of this study is that, because of the paucity of literature on identity construction on LinkedIn, with none in the Aotearoa/New Zealand context, this research served as an exploratory study, and therefore, as the aim of the study is broad, the findings are broad in scope and somewhat tentative. A second limitation that may be raised about this study is that it was situated in Aotearoa/New Zealand, which limited its context, thereby raising the issue around whether these findings are generalisable elsewhere. However as this is an interpretive study the issue of generalisability is not appropriate. That said, the conclusions about tensions between Aotearoa/New Zealand entrepreneurial and professional identity and mainstream Western discourse 
are context-specific, however, they do suggest that similar differences may exist elsewhere, which can be explored.

The findings and limitations of this study suggest several avenues for future research. Firstly, future research can focus on the construction of the two different occupational identities, professional and entrepreneurial, within a virtual context, which will reveal deeper understandings about the construction of each. Such research can also include identifying how individuals reconcile the tensions, or find ways to "hold together necessary incompatibles" (Trethewey \& Ashcraft, 2004, p. 84) in order to function effectively in this context.

Research into the local Aotearoa/New Zealand discourse around that is lacking and needed. entrepreneurship, particularly micro-entrepreneurship, is lacking and needed. This form of enterprise is an expanding phenomenon in Aotearoa/New Zealand (MBIE, 2017), with a drive towards self-employment (Clark \& Douglas, 2014; Duffy \& Pruchniewska, 2017). Such research, therefore, would provide a better understanding that is needed of the personal drivers of economic activity in this field. Finally, research that identifies how LinkedIn's architecture and design are utilised in different contexts, outside the home context of the US, and how design influences local engagement on the site, would be valuable

In conclusion, identifying LinkedIn as a new organisational context for work is possibly still a far-fetched notion for some; however, the experience of the participants in this study confirms it to be an important arena for their daily work lives. Furthermore, in the time that I conducted this research, LinkedIn membership worldwide expanded from 10 million users to 400 million users globally. This significant growth indicates the popularity of the site, and the ubiquity of social media in every aspect of life, including work life, and as such, should be a vital site of research for all aspects of social life.

\section{REFERENCES}

Albert, S. D., \& Whetten, D. (1985). Organizational identity. In L. L. Cummings \& B. M. Staw (Eds.), Research in Organizational Behavior (Vol. 7, pp. 263-295). Greenwich, CT: JAI Press.

Ancona, D., \& Caldwell, D. (1992). Bridging the boundary: External activity and performance in organizational teams. Administrative Science Quarterly, 37( 4), 634-665.

Ashcraft, K. L., \& Mumby, D. K. (2004). Reworking gender: A feminist communicology of organization: Thousand Oaks, CA : Sage, c2004.

Barnett, S. J. . (2019). Identity construction by Aotearoa/New Zealand entrepreneurial professionals on LinkedIn: A tensional approach. (PhD.), Massey University, Albany, Auckland.

Berger, P., \& Luckman, T. (1966). The social construction of reality: A treatise in the sociology of knowledge. New York: Doubleday.

Binder, J. F., Howes, A., \& Smart, D. (2012). Harmony and tension on social network sites: Side effects of increasing online connectivity. Information, Communication \& Society, 15(9), 1279-1297. doi:10.1080/1369118X.2011.648949

Boyd, D. (2007). Social network sites: Public, private, or what? Knowledge Tree, 13.

Burr, V. (1995). An introduction to social constructionism. London: Routledge.

Cheney, G., \& Ashcraft, K. L. (2007). Considering 'The Professional' in Communication Studies: Implications for Theory and Research Within and Beyond the Boundaries of Organizational Communication. Communication Theory, 2, 146-175. Retrieved from http://ezproxy.massey.ac.nz/login?url=http://search.ebscohost.com/login.aspx?direct=true\&db=edsggo\&AN=edsgcl.1 $72821364 \&$ site $=$ eds-live \&scope $=$ site

Cheney, G., Christensen, L.T., Ganesh, S, \& Zorn, T. E. (2011). Organizational communication in an age of globalization: Issues, reflections, practices (Vol. 2nd ed). Long Grove, Ill: Waveland Press.

Clark, Delwyn N., \& Douglas, Heather. (2014). Micro-enterprise growth: Lessons from home-based business in New Zealand. Small Enterprise Research: The Journal of SEAANZ(1), 82. Retrieved from http://ezproxy.massey.ac.nz/login?url=http://search.ebscohost.com/login.aspx?direct=true\&db=edsibc\&AN=edsibc.7 76054436072976\&site $=$ eds-live \&scope $=$ site

Clarke, C. A. , Brown, A. D. , \& Hailey, V. (2009). Working identities? Antagonistic discursive resources and managerial identity. Human Relations, 62(3), 323-352.

Crane, D. (1972). Invisible colleges. Chicago: University of Chicago Press.

DiMicco, J. M., \& Millen, D. R. ( 2007, November). Identity management: Multiple presentations of self in Facebook. Paper presented at the 2007 International ACM conference on supporting group work . ACM.

Donath, J., \& Boyd, D. (2004). Public displays of connection. B.T. Technology Journal, 22(4), 71-82. 
Duffy, B. E., \& Pruchniewska, U. (2017). Gender and self-enterprise in the social media age: A digital double bind. Information, Communication \& Society, 20(6), 843-859. doi:10.1080/1369118X.2017.1291703

Erickson, E. (1974). Dimensions of a new identity. N.Y.: W. W. Norton \& Company.

Fairburn, M. (1989). The ideal society and its enemies: The foundations of modern New Zealand society, 1850-1900. Auckland, N.Z.: Auckland University Press.

Florenthal, B., \& Dykhouse, M. (2012). How college students use LinkedIn, why some don't use it, and why it is important. Paper presented at the DMEF Research Summit, Las Vegas.

Fonseca, M. (2014). Entreprenaissance: The renaissance of entrepreneurship. Retrieved from http://www.intelligenthq.com/startup/entreprenaissance-renaissance-entrepreneurship/

Gee, J. P., Lankshear, C., \& Hull, G. (1996). The new work order: Behind the language of the new capitalism. St. Leonards, N.S.W.: Allen \& Unwin.

Gergen, K. (1997). Social saturation and the populated self. In G. E. Hawisher \& C. L. Selfe (Eds.), Literacy, technology and society: Confronting the issues Upper Saddle River, N.J.: Prentice Hall.

Gill, R. (2017). The entrepreneur in the age of discursive reproduction: Whence comes entrepreneurial identity? In T. N. Duening \& M. L. Metzger (Eds.), Entrepreneurial identity[electronic resource] The process of becoming an entrepreneur. Cheltenham, U.K.: Edward Elgar Publishing Limited.

Gill, R., \& Larson, G. (2014a). Making the ideal (local) entrepreneur: Enterprise discourse, place, and the construction of entrepreneurial identity. Human Relations, 67, 519-542.

Gill, R., \& Larson, G. (2014b). Making the ideal (local) entrepreneur: Place and the regional development of high-tech entrepreneurial identity. Human Relations, 67(5), 519-542. doi:10.1177/0018726713496829

Goffman, E. (1959). The presentation of self in everyday life. Garden City, NY: Doubleday.

Grant, D., \& Cox, J. W. (2017). Using a Discourse Lens to Explore Tensions and Contradictions in Organizational Theory and Change: A Conversation with Linda Putnam. Journal of Change Management, 17(3), 189-202. doi:10.1080/14697017.2017.1299289

Haslam, S. A. (2001). Psychology in organizations. London: SAGE.

Jussila, J.J., Kärkkäinen, H., \& Aramo-Immonen, H. . (2014). Social media utilization in business-to-business relationships of technology industry firms. Computers in Human Behavior, 30, 606-613.

Knight, \& Weedon, A. (2014). Identity and social media. Convergence, 20(3), 257-258. doi:10.1177/1354856514536365

Kraut, R. E., \& Resnick, P. (2011). Building successful online communities: Evidence-based social design. Cambridge, MA: MIT Press.

Kuhn, T. (2006). A 'demented work ethic' and a 'lifestyle firm':discourse, identity, and workplace time commitments. Organization Studies, 27(9), 1339-1358.

Larson, G., \& Gill, R. (2017). Organizations and Identity. Malden, MA., Cambridge, UK.: Polity Press.

Macdonald, K. M. (1995). The sociology of the professions. London: Sage.

Marder, B., Joinson, A., \& Shankar, A. (2012). Every post you make, every pic you take, I'll be watching you: Behind social spheres on Facebook. Paper presented at the 45th Hawaii International Conference on System Sciences.

Marder, B., Joinson, A., Shankar, A., \& Thirlaway, K. (2016). Strength matters: Self-presentation to the strongest audience rather than lowest common denominator when faced with multiple audiences in social network sites. Computers in Human Behavior, 61, 56-62. doi:http://dx.doi.org/10.1016/j.chb.2016.03.005

Marwick, A. (2012). The Public Domain: Social Surveillance in Everyday Life. Surveillance \& Society, 9(4)), 378-393.

Marwick, A., \& Boyd, D. (2011). I tweet honestly, I tweet passionately: Twitter users, context collapse, and the imagined audience. New Media and Society, 13(1), 114-133.

Massey, D. (1994). Space, place, and gender. Cambridge [England]: Polity Press.

MBIE. (2017). Small businesses in New Zealand: How do they compare with larger firms? Retrieved from http://www.mbie.govt.nz/info-services/business/business-growth-agenda/sectors-reports-series/pdf-image-library/thesmall-business-sector-report-and-factsheet/small-business-factsheet-2017.pdf

Michaelidou, N., Siamagka, N.T., \& Christodoulides, G. (2011). Usage, barriers and measurement of social mediamarketing: An exploratory investigation of small and medium B2B brands. Industrial Marketing Management, 40(7), 1153-1159.

Mumby, D. K. (2011). What's cooking in organizational discourse studies? A response to Alvesson and Kärreman. Human Relations, 64(9), 1147-1161. doi:10.1177/0018726711408367

Nardi, B., Whittaker, S., \& Schwartz, H. (2002). Networkers and their activity in intensional networks. The Journal of Computer Supported Cooperative Work 11, 205-242.

Oakes, P. (2004). Social cognition. Oxford: Blackwell Publishing. 
Ollier-Malaterre, A., Rothbard, N. P., \& Berg, J. M. (2013). When worlds collide in cyberspace: How boundary work in online social networks impacts professional relationships. Academy of Management Review, 38(4), 645-669. doi:10.5465/amr.2011.0235

Oslund, C. (2010). Building a Professional Ethos on LinkedIn. In Tatyana Dumova \& Richard Fiordo (Eds.), Handbook of Research on Social Interaction Technologies and Collaboration Software: Concepts and Trends. Hershey, PA, USA: ICI Global.

Paliszkiewicz, J., \& Madra-Sawicka, M. (2016). Impression Management in Social Media: The Example of LinkedIn. Management, 11(3), 203-212. Retrieved from http://ezproxy.massey.ac.nz/login?url=http://search.ebscohost.com/login.aspx?direct=true\&db=bth\&AN=119349087 $\&$ site $=$ eds-live $\&$ scope $=$ site

Papacharissi, Z. (2009). The virtual geographies of social networks: A comparative analysis of Facebook, LinkedIn and ASmallWorld. New Media and Society, 11(1-2), 199-220. doi:10.1177/1461444808099577

Papacharissi, Z. (2011). A networked self. In Z. Papacharissi (Ed.), A networked self: Identity, community and culture on social network sites (pp. 304-318). New York: Routledge.

Postmes, T., Baray, G., Haslam, S. A., Morton, T. A., \& Swaab, R. I. (2006). The dynamics of personal and social identity formation. In T. Postmes \& J. Jetten (Eds.), Individuality and the group: Advances in social identity (pp. 215-236). London: SAGE.

Putnam, L., Fairhurst, Gail T., \& Banghart, Scott. (2016). Contradictions, Dialectics, and Paradoxes in Organizations: A Constitutive Approach. The Academy of Management Annals, 10(1), 65-171. doi:10.1080/19416520.2016.1162421

Quinton, Sarah, \& Wilson, Damien. (2016). Tensions and ties in social media networks: Towards a model of understanding business relationship development and business performance enhancement through the use of LinkedIn. Industrial Marketing Management, 54, 15-24. doi:10.1016/j.indmarman.2015.12.001

Rainie, H., \& Wellman, B. (2012). Networked: The New Social Operating System. Cambridge, Mass: The MIT Press.

Ramirez, A. Jr., Walther, J. B., Burgoon, J. K., \& Sunnafrank, M. (2002). Information-seeking strategies, uncertainty, and computer-mediated communication: Toward a conceptual model. Human Communication Research(2), 213.

Retrieved from

http://ezproxy.massey.ac.nz/login?url=http://search.ebscohost.com/login.aspx?direct=true\&db=edsgea\&AN=edsgcl.8 $5176496 \&$ site $=$ eds-live \&scope $=$ site

Reedy, P., King, D., \& Coupland, C. (2016). Organizing for individuation: Alternative organizing, politics and new identities. Organization Studies, 37(11), 1553-1573. doi:doi:10.1177/0170840616641983

Sampson, K. A., \& Goodrich, C. G. (2009). Making Place: Identity Construction and Community Formation through "Sense of Place" in Westland, New Zealand. Society \& Natural Resources, 22(10), 901-915.

Sargent, Lyman Tower. (2001). Utopianism and the creation of New Zealand national identity. Utopian Studies(1). Retrieved from http://ezproxy.massey.ac.nz/login?url=http://search.ebscohost.com/login.aspx?direct=true\&db=edsglr\&AN=edsgcl.7 $7186827 \&$ site $=$ eds-live \&scope $=$ site

Shirky, C. (2008). Here comes everybody: The power of organizing without organizations. NY: Penguin Press.

Spoonley, Paul. (2014). New diversity, old anxieties in New Zealand: the complex identity politics and engagement of a settler society. Ethnic and Racial Studies, 38(4), 650-661. doi:10.1080/01419870.2015.980292

Tracy, S. J., \& Trethewey, A. ( 2005). Fracturing the real-self $\leftrightarrow$ fake-self dichotomy: Moving toward "crystallized" organizational discourses and identities. Communication Theory, 15, 168-195.

Trethewey, A., \& Ashcraft, K. L. (2004). Special issue introduction. Practicing disorganization: The development of applied perspectives on living with tension. Journal of Applied Communication Research, 32, 81-88.

Watson, T. J. (2008). Managing Identity: Identity Work, Personal Predicaments and Structural Circumstances. Organization, 15(1), 121-143.

Whitworth, B., \& Liu, T. (2013). Politeness as a Social Computing Requirement Examining the Concepts, Issues, and Implications of Internet Trolling (pp. 88-104). Hershey, PA, USA: IGI Global.

Wong, J. (2012). The rise of the micro-entrepreneurship economy. Retrieved from https://www.fastcompany.com/2679903/the-rise-of-the-micro-entrepreneurship-economy

Woo, DaJung, Putnam, L., \& Riforgiate, Sarah E. (2017). Identity Work and Tensions in Organizational Internships: A Comparative Analysis. Western Journal of Communication, 81(5), 560-581. doi:10.1080/10570314.2017.1312510

Young, K. (2013). Managing online identity and diverse social networks on Facebook. Webology, 10(2), 1-18. Retrieved from

http://ezproxy.massey.ac.nz/login?url=http://search.ebscohost.com/login.aspx?direct=true\&db=edsdoj\&AN=edsdoj.5 4b68d0451914875ad20109a34f7628d\&site=eds-live \&scope $=$ site 